\title{
Article \\ Improve the Mechanical Properties of Mg-3Al-1Zn Alloy via Simultaneous Annealing and Loading
}

\author{
Jiejun $\mathrm{He}^{1, *}$ and Lushu $\mathrm{Wu}^{2}$ \\ 1 School of Materials and Energy Engineering, Guizhou Institute of Technology, Guiyang 550003, China \\ 2 School of Mechanical Engineering, Guizhou Institute of Technology, Guiyang 550003, China; \\ wulushu@git.edu.cn \\ * Correspondence: hejiejungz@126.com or hejiejun@git.edu.cn
}

check for updates

Citation: He, J.; Wu, L. Improve the Mechanical Properties of

$\mathrm{Mg}-3 \mathrm{Al}-1 \mathrm{Zn}$ Alloy via Simultaneous Annealing and Loading. Metals 2022, 12, 309. https://doi.org/10.3390/ met12020309

Academic Editor: Menachem Bamberger

Received: 22 December 2021

Accepted: 8 February 2022

Published: 10 February 2022

Publisher's Note: MDPI stays neutral with regard to jurisdictional claims in published maps and institutional affiliations.

Copyright: (C) 2022 by the authors. Licensee MDPI, Basel, Switzerland. This article is an open access article distributed under the terms and conditions of the Creative Commons Attribution (CC BY) license (https:// creativecommons.org/licenses/by/ $4.0 /)$.

\begin{abstract}
A strengthening phenomenon has been demonstrated in the $\mathrm{Mg}-3 \mathrm{Al}-1 \mathrm{Zn}$ (AZ31) alloy after simultaneous annealing and loading at $180{ }^{\circ} \mathrm{C}$. The microstructural analysis reveals that a few second-phase particles appear in the material after direct annealing at $180{ }^{\circ} \mathrm{C}$ for $20 \mathrm{~h}$. However, a higher quantity of the second-phase particles $\left(\mathrm{Al}_{12} \mathrm{Mg}_{17}\right)$ is observed in the alloy after simultaneous annealing and loading. Further, a high stress is observed to be more beneficial for the precipitation of the particles. It is speculated that the stress applied during annealing can provide a better condition for the nucleation of the precipitates. The enhanced extent of precipitates may play a significant role in preventing the dislocation gliding, thus, leading to a strengthening effect. The observed phenomenon may also provide a novel strategy for strengthening the magnesium alloys.
\end{abstract}

Keywords: magnesium alloys; second phase; annealing; strengthening; yield stress

\section{Introduction}

Magnesium and its alloys have received significant research attention owing to the lightweight structure, recyclability and abundance [1-3]. However, a wide range of applications of the magnesium alloys is restricted due to their poor formability near room temperature and relatively low mechanical properties in contrast to the conventional structural materials, e.g., steels and aluminum alloys. Thus, improving the mechanical properties of the magnesium alloys has attracted a significant attention in the recent years. As a result, a number of high-strength magnesium alloys have been developed for industrial applications. The methods to enhance the mechanical properties of the magnesium alloys include alloying or compositing, plastic processing and heat treatment. The alloying or compositing aims to refine the grain size, generate a second phase, achieve solution strengthening, etc. For instance, Liu et al. [4] reported that the compressive properties of the $\mathrm{Mg}-4 \mathrm{Y}-1 \mathrm{Zn}-1 \mathrm{Cu}$ alloy could be dramatically enhanced by incorporating $\mathrm{Cu}$. The compressive strength was observed to reach $480 \mathrm{MPa}$. In another study, Feng et al. [5] fabricated an ultra-high strength $\mathrm{Mg}-3 \mathrm{Al}-1 \mathrm{Zn}$ alloy by adding $0.2 \mathrm{wt} \% \mathrm{MgO}$, leading to a tensile yield stress of $459 \mathrm{MPa}$ and an ultimate tensile strength of $519 \mathrm{MPa}$. A number of literature studies have reported the development of the high-strength magnesium alloys, especially by adding the rare-earth elements [6,7]. During the plastic processing method, the severe plastic deformation is observed to be effective in refining the grain size, thus, enhancing the yielding in magnesium and its alloys [8,9]. Secondly, the plastic deformation processes, e.g., pre-compression [10], pre-torsion [11] and pre-rolling [12], affect the subsequent deformation. The heat treatment or heat treatment combined with pre-strain often leads to the solute strengthening, precipitation strengthening, grain refining by recrystallization, etc. Nie et al. [13] reported an unusual phenomenon in the $\mathrm{Mg}-\mathrm{Gd}$ alloys where the equilibrium segregation of the solute atoms in the twin boundaries provided a pinning effect, leading to an annealing hardening effect. Zhao et al. [14] observed that the $\{10-12\}$ twins in a pre-strained Mg AZ31 plate (pre-compression along the transverse direction) 
were completely removed by the subsequent annealing, and the disappearance of the pre-existing $\{10-12\}$ twins led to a transition from a detwinning predominant deformation to a basal slip predominant deformation. Therefore, the annealing hardening phenomenon is observed to appear on compressing along the normal direction.

Though many methods have been developed for strengthening magnesium and its alloys, a majority of these suffer from a variety of deficiencies. For instance, the addition of $0.2 \mathrm{wt} \% \mathrm{MgO}$ to the magnesium alloy AZ31 can result in a high yield stress [5]; however, the elongation to failure is reduced to $3.2 \%$, indicating difficulties in processing. The addition of the rare-earth elements leads to the similar issues, along with being uneconomical. Severe plastic deformation is effective for strengthening, however, it is difficult to process the largesized components. In addition, this method requires cumbersome mould design, processing and maintenance. A large amount of precipitates can effectively strengthen materials but the precipitates cannot grow too fast. However, to obtain a large amount of precipitates a long ageing time is often needed. It is reported that the yield stress of pre-strained magnesium alloy increased at first and then decreased during subsequent annealing, despite a higher quantity of precipitates that was obtained when the annealing time was longer [15]. It looks as though that the recovery produced by a relatively long annealing time may also affect the mechanical properties. If a high quantity of the precipitates can be obtained in a relatively short time, it may be beneficial for strengthening material. In this study, a precipitation strengthening method involving simultaneous annealing and loading is reported. From this, it is hoped that a large amount of precipitates can be obtained in a relatively short time and notably strengthen the material. AZ31 is one of the typical commercial magnesium alloys. Second phase can be obtained if there is appropriate processing. The proposed method is envisaged to provide a novel strategy for strengthening the magnesium alloys.

\section{Materials and Experimental Procedures}

The starting material in this study was a commercial AZ31 extruded rod. The chemical composition of the AZ31 alloy is given in Table 1. No obvious twins were observed in the material, and it exhibited nearly equiaxed grains with a mean grain size of $20 \pm 3 \mu \mathrm{m}$ (Figure 1).

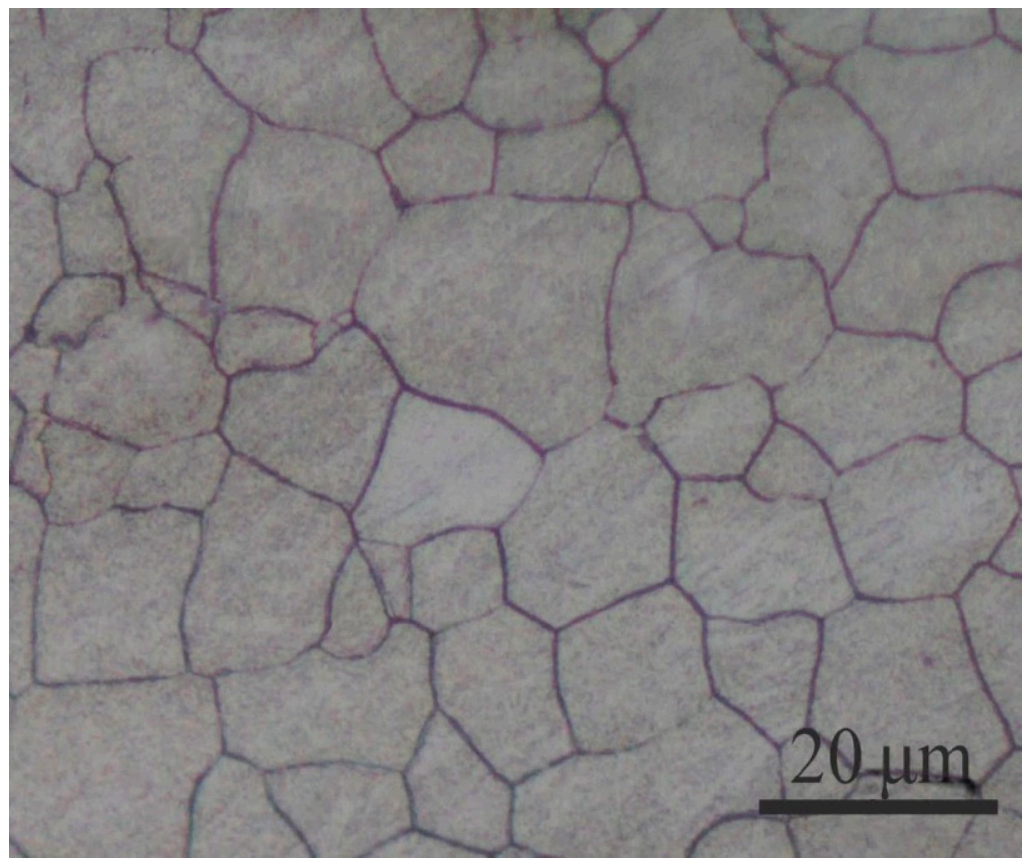

Figure 1. The optical microstructure of the as-received material used in this study. 
Table 1. Compositions of AZ31 magnesium alloy (mass\%) used in this study.

\begin{tabular}{lcccccccc}
\hline Element & Al & Zn & Mn & Si & Ni & Fe & Cu & Mg \\
\hline mass $\%$ & 3 & 1 & 0.5 & 0.0075 & 0.0007 & 0.003 & 0.0025 & balance \\
\hline
\end{tabular}

A diffusion welding furnace with a loading system (Figure 2) was used for the heat treatment. A metallic platen was used for the loading purposes. The maximum load was $100 \mathrm{kN}$, and a constant load was maintained for $20 \mathrm{~h}$ during the heating progress. The specimens ( $6 \mathrm{~mm}$ diameter and $9 \mathrm{~mm}$ height) were machined from the extruded rod along the extrusion direction. The heating temperature was chosen to be $180{ }^{\circ} \mathrm{C}$ to avoid the grain growth. In order to investigate the effect of the annealing and loading conditions on the microstructural and mechanical evolution, a few specimens were subjected to the single annealing, whereas the other specimens were subjected to the simultaneous annealing and loading processes.

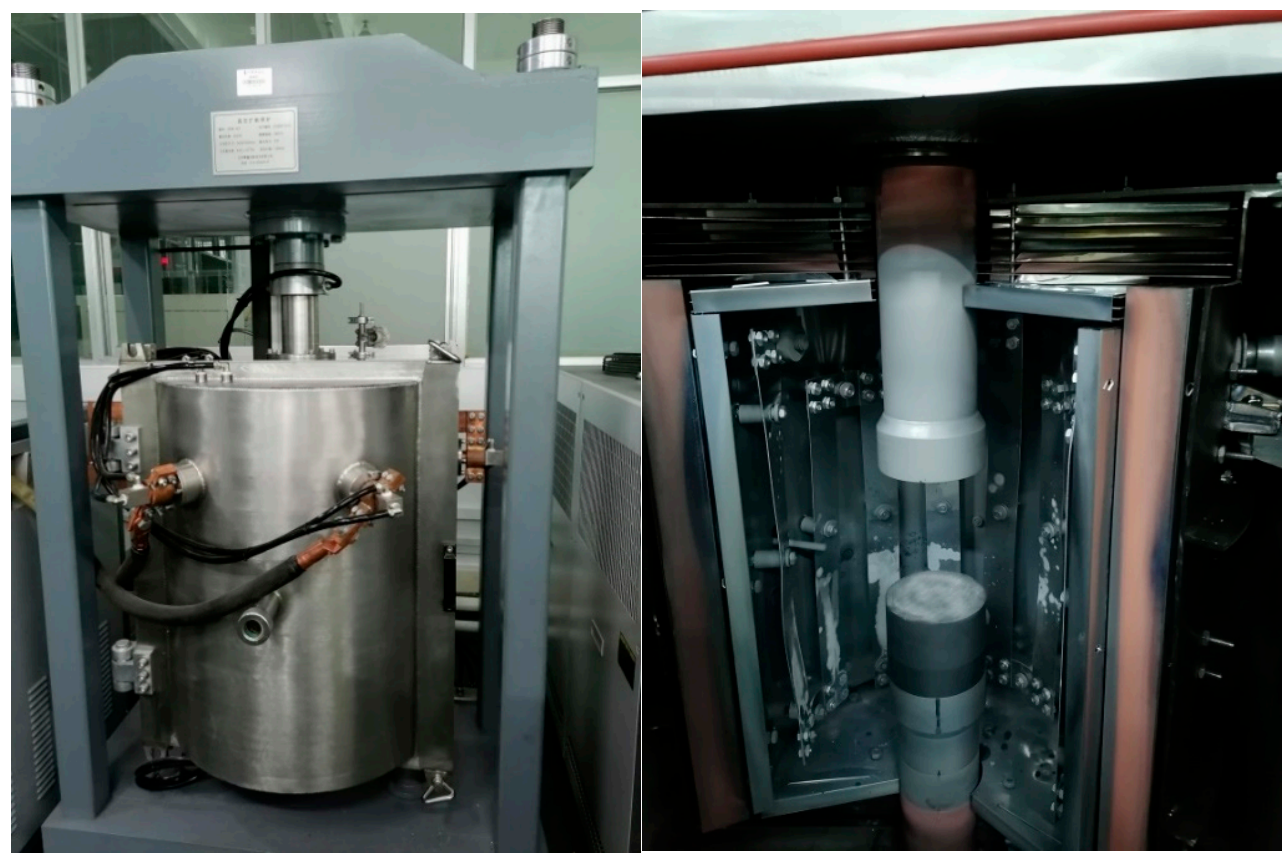

Figure 2. The image of the diffusion welding furnace with a loading system used in this study.

The experimental procedure is shown in Figure 3. The specimens subjected to the single annealing were compressed to failure to measure the mechanical properties along the extruded direction (ED) at room temperature, as illustrated in Figure 3a. Further, the specimens subjected to the simultaneous annealing and loading were reloaded to failure at room temperature, as shown in Figure 3b. All these mechanical tests were conducted by using a CMT5105 material testing machine (MTS LTD, Shenzhen, China) at a constant rate of $10^{-3} \mathrm{~s}^{-1}$. The microstructural observation was carried out by using optical microscopy (OM). In addition, scanning electron microscopy (SEM, Nova Nano SEM 450, FEI LTD, Hillsboro, OR, USA) was carried out using an accelerating voltage of $20 \mathrm{kV}$ after careful polishing and etching with an acetic picral solution containing $5 \mathrm{~mL}$ acetic acid, $6 \mathrm{~g}$ picric acid, $10 \mathrm{~mL} \mathrm{H}_{2} \mathrm{O}$ and $100 \mathrm{~mL}$ ethanol. The pole figures were measured using a Rigaku D/max-2500 X-ray diffractometer (XRD, Rigaku, Tokyo, Japan) to observe the cross-section, using $\mathrm{Cu} \mathrm{k} \mathrm{k}_{\alpha}$ radiation (wave length $\lambda=0.15406 \mathrm{~nm}$ ) at $45 \mathrm{kV}$ and $150 \mathrm{~mA}$ with a sample tilt angle ranging from $0 \sim 80^{\circ}$. In addition, the XRD patterns were also obtained at $40 \mathrm{kV}$ and $150 \mathrm{~mA}$ for identifying the precipitates. The electron backscattered diffraction (EBSD) analysis was carried out using the FIE Nova SEM 450 scanning electron microscope (FEI LTD, Hillsboro, OR, USA) equipped with an TSL OIM-EBSD system (TSL, Tennessee, TN, 
USA) with a step size of $0.5 \mu \mathrm{m}$. The samples for EBSD were mechanically ground, followed by the electrochemical polishing in a commercial AC2 solution. The TSL OIM analysis software (TSL, Tennessee, TN, USA) was utilized to process the data obtained from the electron backscattered diffraction.

(a)

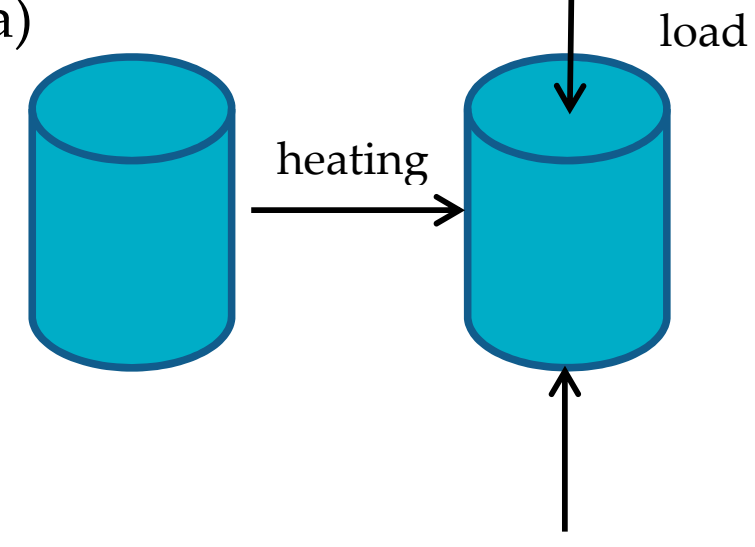

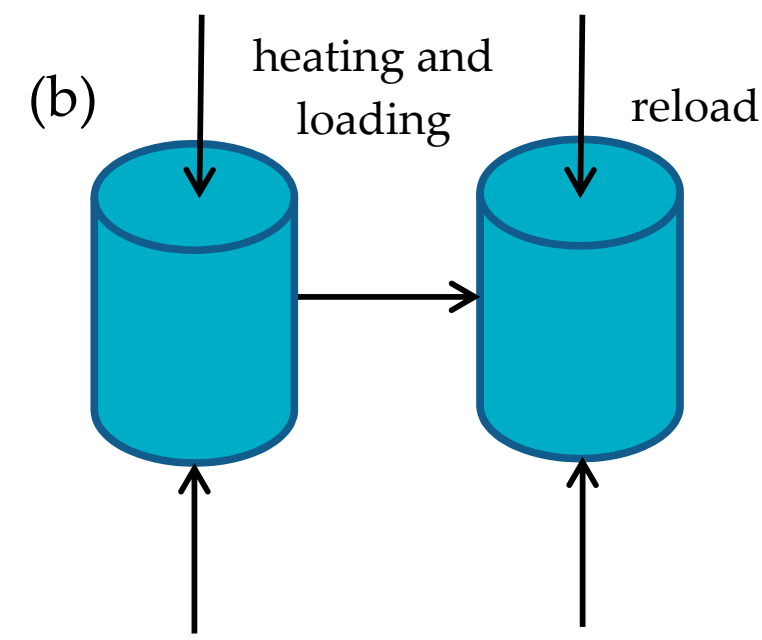

Figure 3. The schematic drawings of the experimental procedure employed in this study: (a) the smaple subjected to single annealing and then loaded to failure at room temperature and (b) the sample subjected to simultaneous annealing and loading and then reloaded to failure at room temperature. The arrows indicate stress direction.

\section{Results and Discussion}

\subsection{Microstructural Evolution as a Function of the Annealing and Loading Conditions}

Twins and twin boundaries represent the vital sites for the solute segregation [13] and nucleation of the second-phase particles [15]. In this study, the effect of the different annealing and loading conditions on the precipitation behavior in the magnesium alloy AZ31 was investigated. The yield stress of the AZ31 alloy used in this study is about $110 \mathrm{MPa}$. In order to avoid the effect of twins and twin boundaries on the precipitation behavior, the applied stress in this study was maintained to be lower than the yield stress, such that no plastic deformation occurred during loading. Therefore, the effect of twins and twin boundaries on the precipitation behavior was neglected. As shown in Figure 1, the microstructure of the as-received alloy AZ31 is free of any twinning. This indicates that there will be no solute segregation and precipitation in the twins and twin boundaries on annealing. Thus, annealing hardening caused by the solute segregation in the twin boundaries was neglected in this study. In order to identify the possible second phase in the alloys, the SEM analysis was carried out to characterize the microstructure. As shown in Figure $4 \mathrm{a}$, in the as-received alloy, a small number of second-phase particles can be observed in the grain boundaries. On annealing the specimen at $180^{\circ} \mathrm{C}$ for $20 \mathrm{~h}$, as illustrated in Figure $4 \mathrm{~b}$, a small number of second-phase particles appeared inside the grains besides the grain boundaries. However, the precipitation behavior after simultaneous annealing and loading is noted to be significantly different as compared to the single annealing process. As shown in Figure $4 \mathrm{c}$, applying a stress of $30 \mathrm{MPa}$ and annealing at $180^{\circ} \mathrm{C}$ for $20 \mathrm{~h}$ leads to the generation of a large number of second-phase particles in the alloy. A stress exceeding $60 \mathrm{MPa}$ is noted to be more beneficial for precipitation, as shown in Figure 4d. As a result, a large number of second-phase particles are noticed in the alloy. 


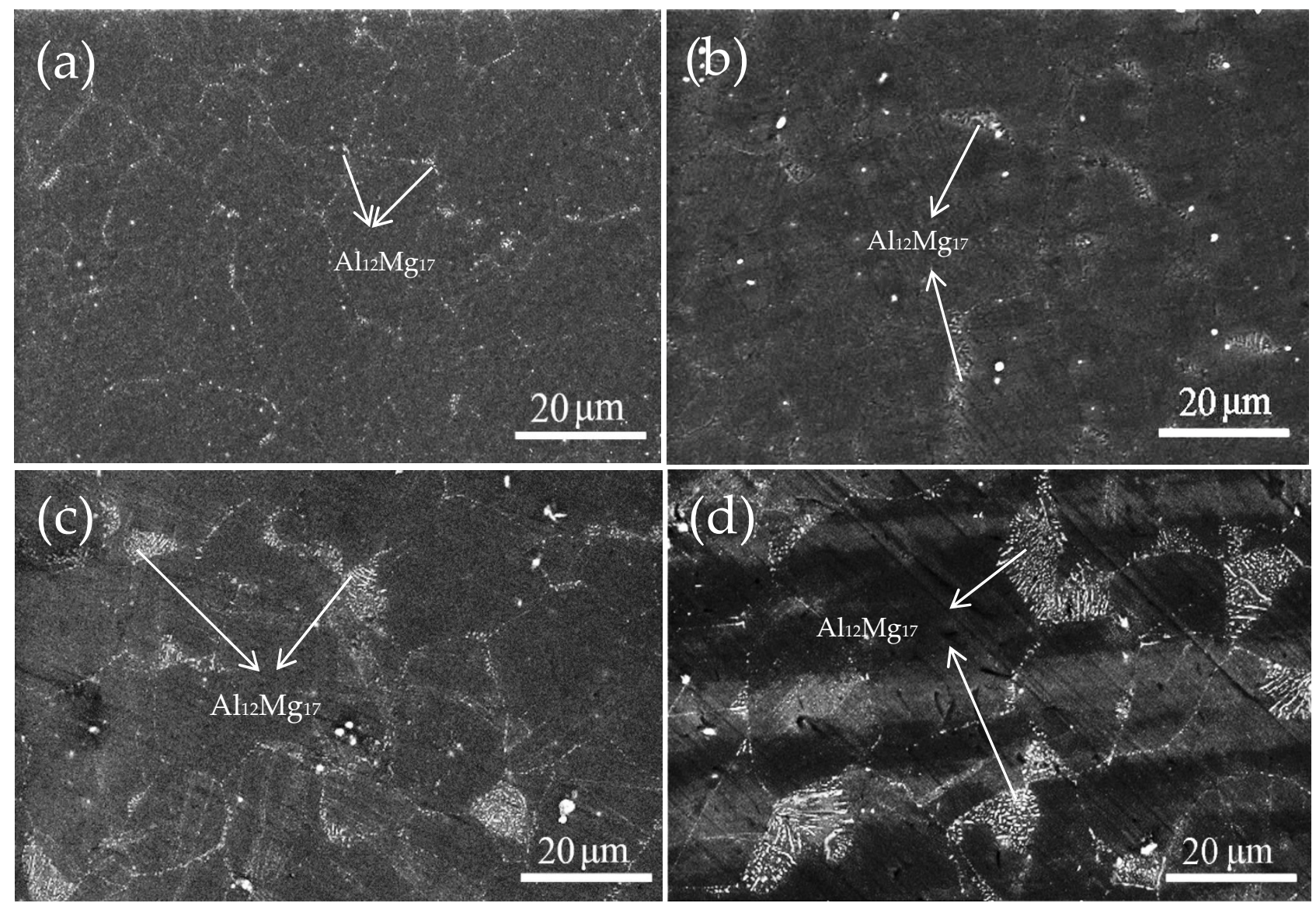

Figure 4. The SEM micrographs demonstrating the microstructure of (a) as-received material, (b) the specimen annealed at $180{ }^{\circ} \mathrm{C}$ for $20 \mathrm{~h}$, (c) the specimen subjected to a stress of $30 \mathrm{MPa}$ and annealed at $180{ }^{\circ} \mathrm{C}$ for $20 \mathrm{~h}$ and (d) the specimen subjected to a stress of $60 \mathrm{MPa}$ and annealed at $180{ }^{\circ} \mathrm{C}$ for $20 \mathrm{~h}$. The white particles represent the second phase $\mathrm{Al}_{12} \mathrm{Mg}_{17}$.

The EBSD analysis of the initial extruded rod shows no obvious twins in the alloy, as hown in Figure 5a,b. As observed in Figure 5c, on applying a stress of $60 \mathrm{MPa}$ and annealing at $180{ }^{\circ} \mathrm{C}$ for $20 \mathrm{~h}$, a large number of black particles appeared in the alloy, which cannot be characterized as the magnesium lattice. In addition, no obvious twins appeared in the alloy as the stress is lower than the yield stress. A small amount of the boundaries with a disorientation of $\sim 86 \pm 5^{\circ}$ were found in the obtained magnesium alloy AZ31 and the specimen subjected to a stress of $60 \mathrm{MPa}$ and annealed at $180{ }^{\circ} \mathrm{C}$ for $20 \mathrm{~h}$, as indicated in red in Figure 5b,d. They may be $\{10-12\}$ twins formed during hot extrusion or high angle grain boundaries.

The XRD results indicate that the as-received AZ31 alloy is nearly a single-phase alloy, with no obvious patterns exhibiting the presence of the second phase, as illustrated in Figure 6a. However, the XRD patterns confirm the presence of the second phase in the specimen subjected to the simultaneous annealing and loading, with the second phase determined to be $\mathrm{Al}_{12} \mathrm{Mg}_{17}$, as shown in Figure $6 \mathrm{~b}$. 

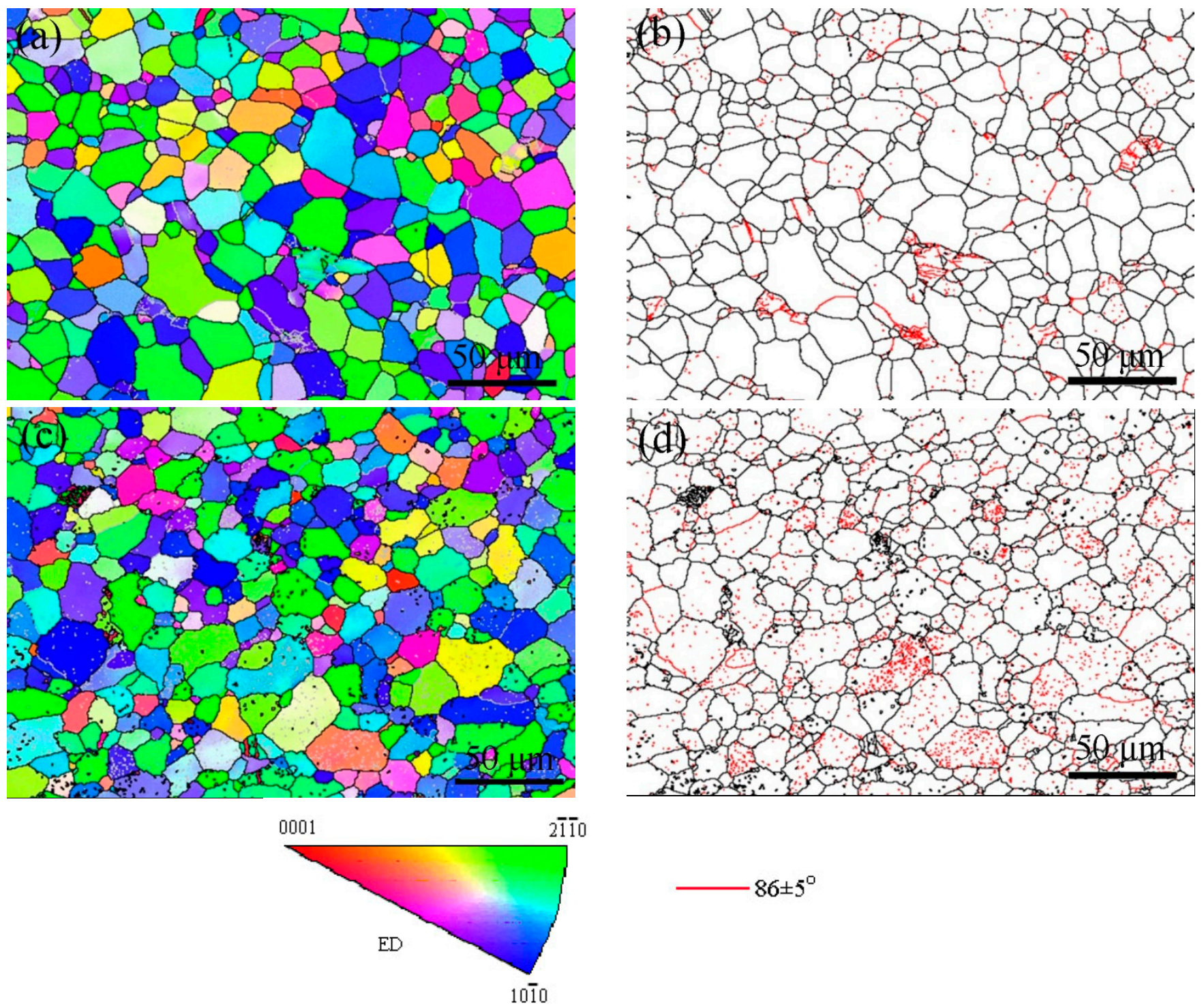

$2 \overline{1} \overline{1} 0$

Figure 5. $(\mathbf{a}, \mathbf{b})$ represent the inverse pole figure and grain and twin boundaries of the extruded rod, respectively; (c,d) illustrate the inverse pole figure and grain and twin boundaries of the specimen subjected to a stress of $60 \mathrm{MPa}$ and annealed at $180{ }^{\circ} \mathrm{C}$ for $20 \mathrm{~h}$, respectively. Red lines represent the boundaries with a disorientation of $\sim 86 \pm 5^{\circ}$.

As the applied stress was lower than the yield stress in this study, no dislocation gliding and twin nucleation occurred in the alloy during the simultaneous annealing and loading. Therefore, no common work-hardening phenomenon was observed during the simultaneous annealing and loading. In the magnesium alloys, the solute atoms, such as $\mathrm{Al}$ and $\mathrm{Zn}$, often segregate in the grain boundaries or occupy the normal magnesium sites owing to their close atomic sizes. Due to the misfit between magnesium and the main alloying atoms such as $\mathrm{Al}$ and $\mathrm{Zn}$, the magnesium alloy AZ31 is generally in a higher-energy state as compared to the pure magnesium. The lattice misfit is responsible for solute strengthening in the alloy. Generally speaking, for a particular alloy, the solute strengthening is often inferior than the second-phase strengthening in the metallic materials if the precipitates do not grow too fast and become too large. If so, the second-phase particles often play a more important role in preventing the dislocation gliding. Therefore, in a majority of the alloys, a transformation of the solid solution to the second-phase particles usually strengthens the material due to the second-phase strengthening. Fu et al. [16] reported that a high pressure can promote the second-phase nucleation during 
aging, thus enhancing the mechanical properties. In the magnesium alloys, the alloying atoms often occupy the normal $\mathrm{Mg}$ sites as their atomic sizes are similar. If the atomic size of the alloying atoms is higher than that of $\mathrm{Mg}$, as shown in Figure $7 \mathrm{a}$, the repulsion between $\mathrm{Mg}$ and alloying atoms will increase in the presence of an external pressure. The alloying atoms will be repelled due to the presence of the compressive stress, thus leading to precipitation during aging. It is well known that the grain boundaries are the preferred nucleation sites for the second-phase particles as the atomic arrangement in the grain boundaries is irregular. Therefore, the white particles are formed preferentially in the grain boundaries during annealing. If the atomic size of the solute atoms, such as $\mathrm{Al}$ and $\mathrm{Zn}$, is smaller than that of $\mathrm{Mg}$, as shown in Figure $\mathrm{7b}$, there is an attraction between the $\mathrm{Mg}$ and solute atoms. If the material is subjected to a compressive stress, the distance between the $\mathrm{Mg}$ and solute atoms will be reduced, and the attraction between these atoms will decline. This indicates that the solute atoms will be more active during the heat treatment combined with loading, thus leading to enhanced precipitation during aging. Our previous study [17] also reported that the pre-strain could promote the second-phase nucleation during the subsequent annealing owing to the internal stress in the pre-strained alloy.
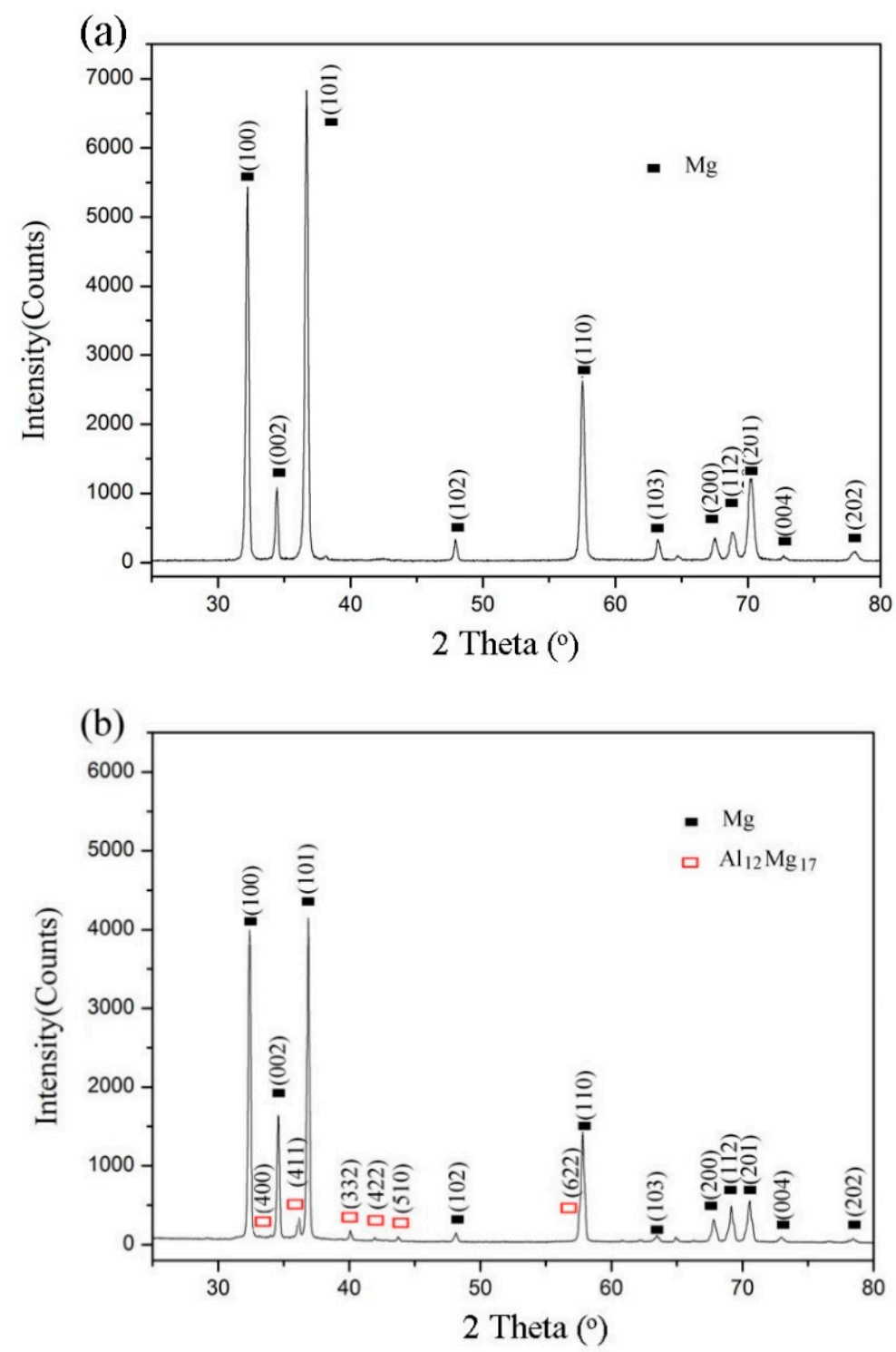

Figure 6. The XRD patterns of (a) the as-received alloy and (b) the specimen subjected a stress of $60 \mathrm{MPa}$ and annealed at $180^{\circ} \mathrm{C}$ for $20 \mathrm{~h}$. 


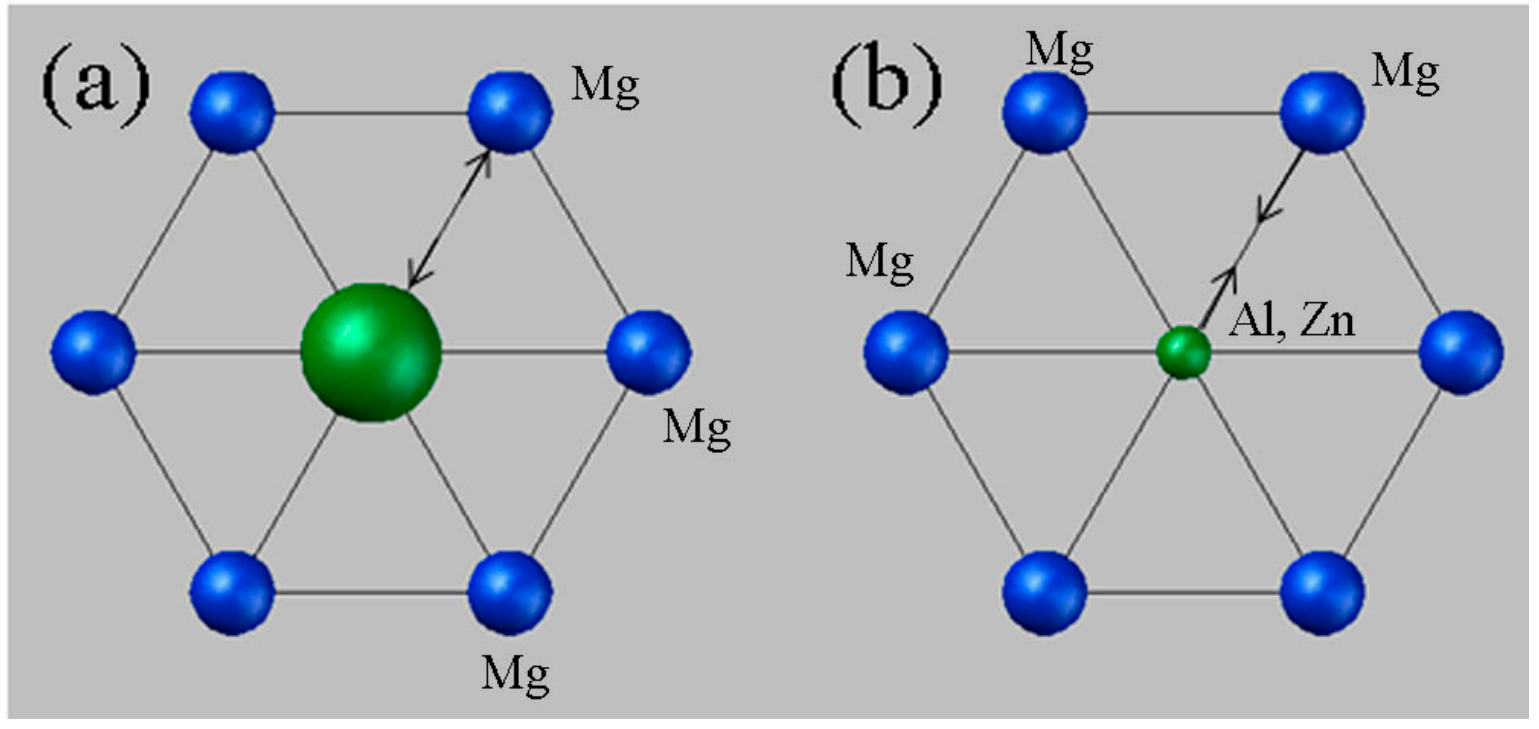

Figure 7. The schematic drawings depicting the relation between the $\mathrm{Mg}$ and large solute atoms (a) and $\mathrm{Mg}$ and small solute atoms (b).

\subsection{Effect of Simultaneous Annealing and Loading on Mechanical Properties of Extruded AZ31 Alloys}

For the as-received AZ31 alloy, the yield stress was about $110 \mathrm{MPa}$. Annealing the material at $180^{\circ} \mathrm{C}$ for $20 \mathrm{~h}$ led to a minor reduction in the yield stress, as shown in Figure 8 . This indicates that the material is softened by annealing at $180{ }^{\circ} \mathrm{C}$ for $20 \mathrm{~h}$. However, the strain-stress curve (Figure 8) illustrates that in contrast to the single heat treatment, stressing the material at $30 \mathrm{MPa}$ and annealing at $180^{\circ} \mathrm{C}$ for $20 \mathrm{~h}$ led to its strengthening and corresponding increase in the yield stress to about $135 \mathrm{MPa}$. Applying a stress of $60 \mathrm{MPa}$ and annealing at $180^{\circ} \mathrm{C}$ for $20 \mathrm{~h}$ led to an increase of $50 \mathrm{MPa}$ in the yield stress as compared to the as-received material. The mechanical evolution as a function of treatment and microstructure evolution is summarized in Table 2.

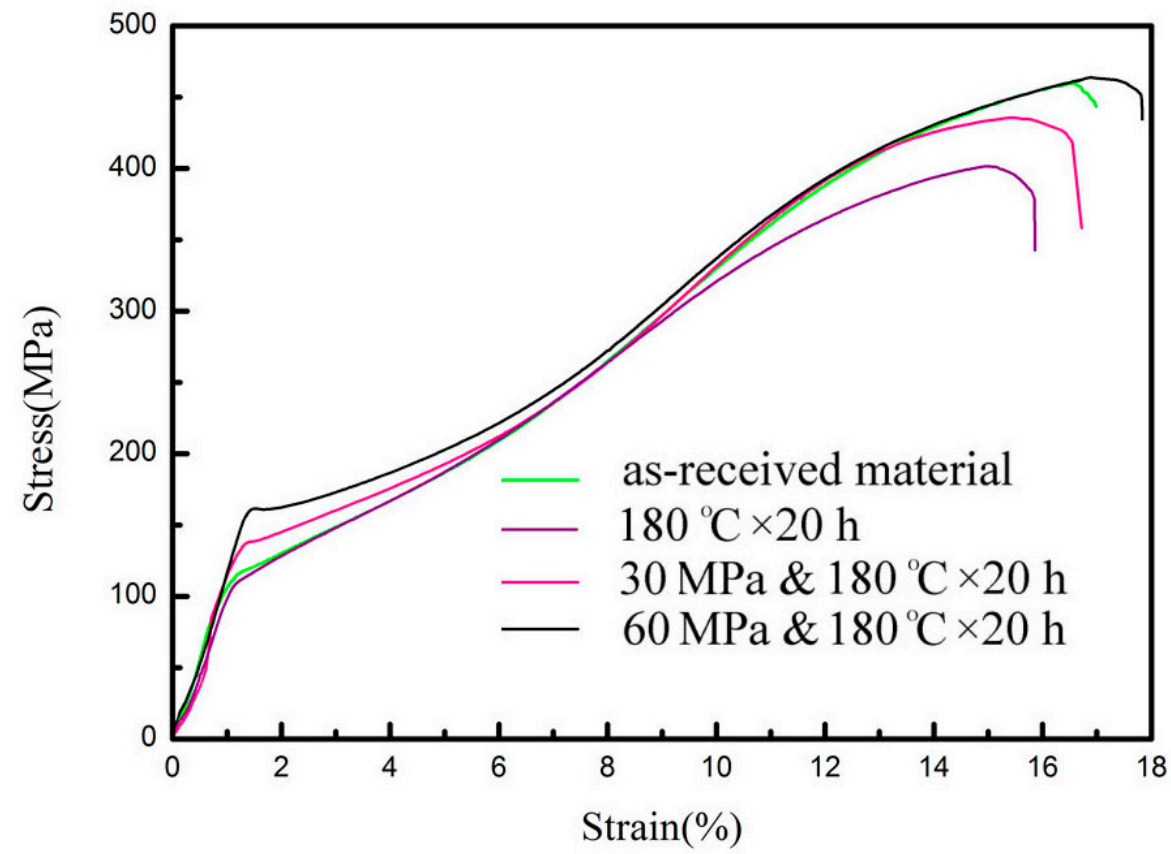

Figure 8. The stress-strain curves of the as-received AZ31 alloy and specimens subjected to the different annealing and loading conditions. 
Table 2. A summary of the relationship among treatment, microstructure and mechanical property.

\begin{tabular}{cccc}
\hline Alloy & Treatment & Microstructure & Yield Stress \\
\hline 1 & as-received & Figure 4a & $110 \mathrm{MPa}$ \\
2 & $180^{\circ} \mathrm{C} \times 20 \mathrm{~h}$ & Figure $4 \mathrm{~b}$ & $105 \mathrm{MPa}$ \\
3 & $30 \mathrm{MPa}$ and $180^{\circ} \mathrm{C} \times 20 \mathrm{~h}$ & Figure $4 \mathrm{c}$ & $135 \mathrm{MPa}$ \\
4 & $60 \mathrm{MPa}$ and $180^{\circ} \mathrm{C} \times 20 \mathrm{~h}$ & Figure $4 \mathrm{~d}$ & $160 \mathrm{MPa}$ \\
\hline
\end{tabular}

In magnesium and its alloys, the texture evolution impacts the mechanical properties during processing or annealing. In order to characterize the texture evolution during annealing, the XRD analysis was performed on the cross-section to measure the pole figures to confirm the texture evolution. Figure 9 shows the $\{0002\}$ pole figures of the initial extruded sample (Figure 9a) and sample subjected to annealing (at $180{ }^{\circ} \mathrm{C}$ for $20 \mathrm{~h}$ ) as well as a stress of $60 \mathrm{MPa}$ (Figure 9b). As can be observed in Figure 9, it seems that the simultaneous annealing and loading shows a slight weakening effect in texture. However, there was no obvious plastic deformation when the material was subjected to simultaneous annealing and loading because the applied stress $(60 \mathrm{MPa})$ was obviously low than the yield stress of the initial material $(\sim 110 \mathrm{MPa})$. This means the effect of plastic deformation on texture evolution can be neglected in this study. Annealing may affect texture evolution, especially in the case of appearance of recrystallization. However, the annealing temperature chosen in this study was relatively low to avoid recrystallization and grain growth, thus, it can be proposed that the stress and annealing in this study had little effect on texture evolution. The deviation in texture shown in Figure 9 may be the differences between selected areas of the initial material. Although there is deviation in the textures of these two samples, the crystal orientations in these two samples are still very similar. Therefore, the effect of texture evolution on the mechanical properties can be neglected in this study. The grain growth and its effect on the yielding behavior also can be neglected as the annealing temperature in this study is not sufficient to induce the grain growth.
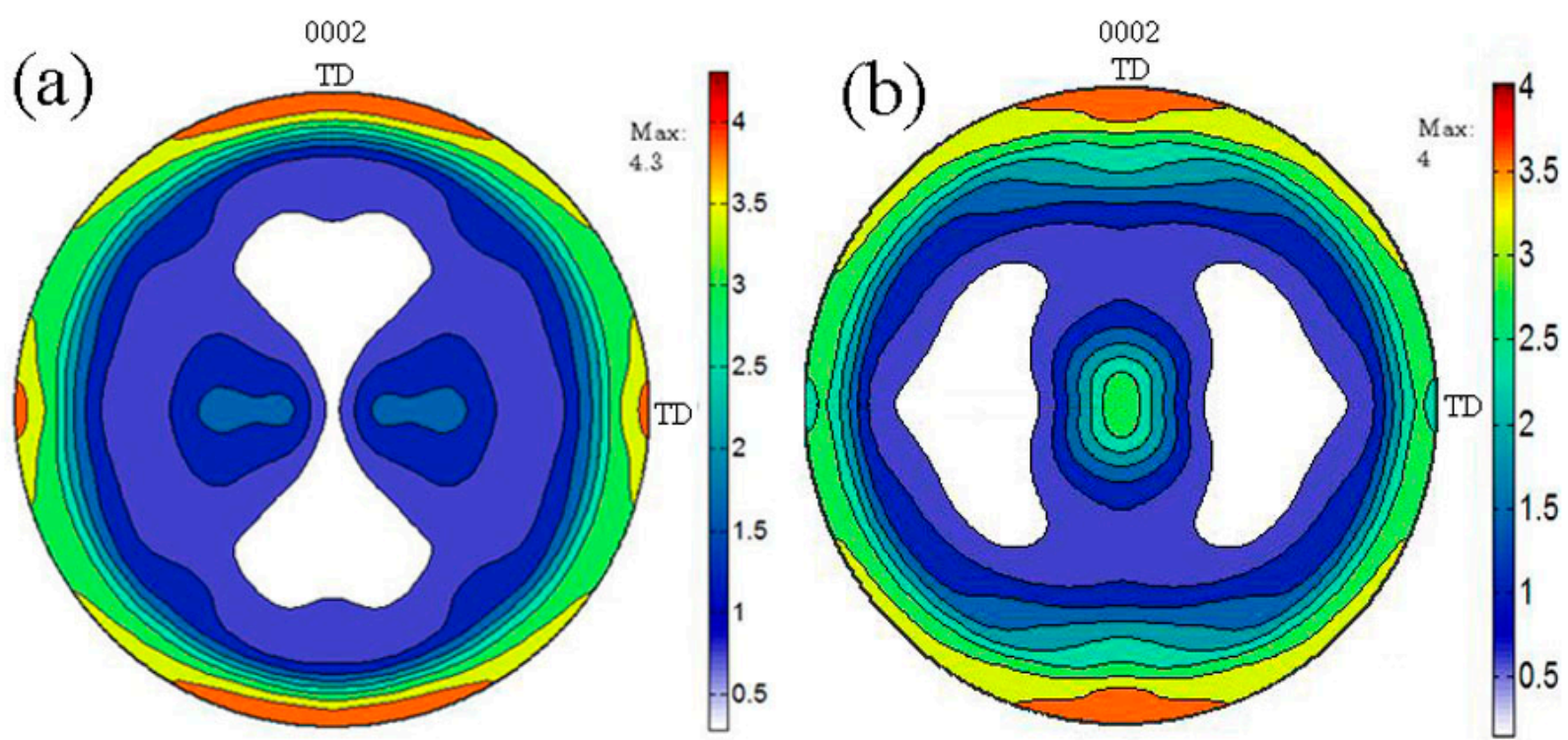

Figure 9. (a) The $\{0002\}$ pole figures of the as-received AZ31 alloy and (b) the specimen subjected to a stress of $60 \mathrm{MPa}$ and annealed at $180{ }^{\circ} \mathrm{C}$ for $20 \mathrm{~h}$. TD stands for the transverse direction of the extruded bar.

Several annealing hardening mechanisms have been reported previously. On subjecting a magnesium alloy to the plastic deformation and subsequently annealing at a suitable temperature, the periodic segregation of the solute atoms may occur in the twin boundaries, and an annealing hardening behavior is observed [13]. In this study, the applied stress is 
lower than the yield stress, and the microstructural characterization does not reveal any twins in the alloy. Therefore, it can be concluded that the annealing hardening reported by Nie et al. does not occur in this study due to the absence of any twins during the simultaneous annealing and loading. However, the solute atoms may segregate in the grain boundaries or form a new intermetallic compound in the grain boundaries during annealing. The energy dispersive spectroscopy (EDS) analysis shows that the atomic fraction of the $\mathrm{Al}$ and $\mathrm{Zn}$ atoms in the grain boundary is far higher than that inside the grains, as illustrated in Figure 10.
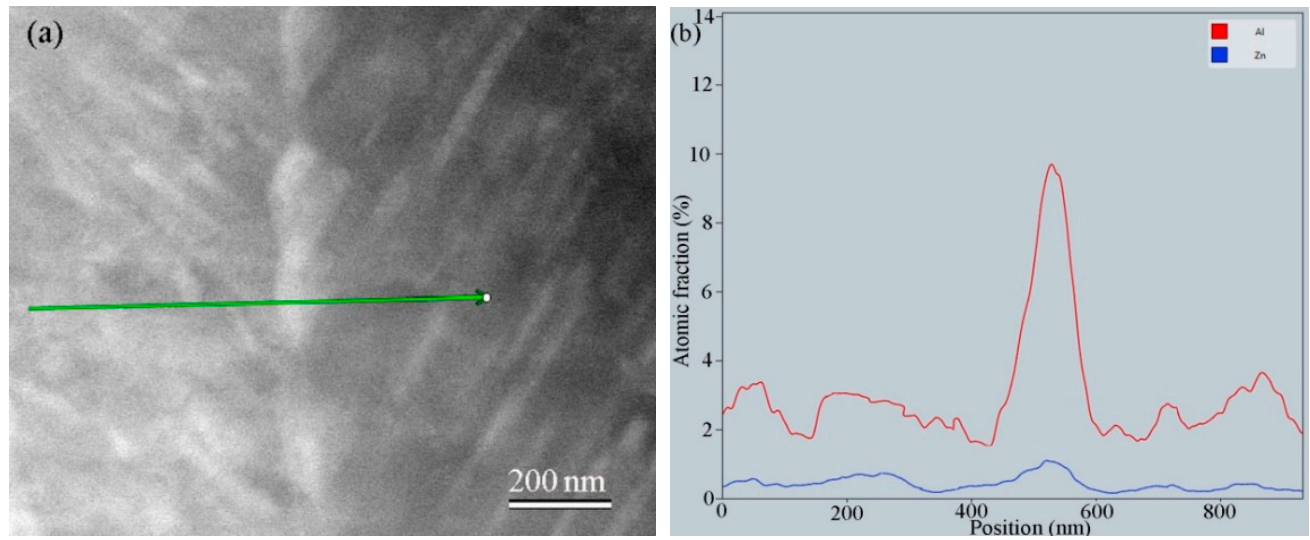

Figure 10. The EDS analysis exhibiting the atomic fraction of $\mathrm{Al}$ and $\mathrm{Zn}$ in a grain boundary and inside a grain: (a) Linear scanning across a twin boundary and (b) the change of atomic fraction of $\mathrm{Al}$ and $\mathrm{Zn}$ along the scanning route. The blue line indicates the scanning route.

It is clear that the second-phase particles are formed in the grain boundaries preferentially during annealing. The second-phase particles in the grain boundaries act as an obstacle to the dislocation gliding due to the differences in the crystal structure. Thus, an enhanced strength is observed during the subsequent deformation. In addition, a small amount of the $\mathrm{Al}$ and $\mathrm{Zn}$ atoms may segregate in the grain boundaries independently. It is difficult to establish whether the segregation of the solutes in the grain boundaries provides a strengthening effect, as the amount of the substitutional solutes inside the grains decreases during annealing. However, the yield drop phenomenon during annealing illustrates that the solute movement from the grains to the grain boundaries cannot provide an obvious strengthening effect. Continuing with annealing and loading, an increasing number of second-phase particles nucleate and grow up inside the grains. These particles pin the dislocation gliding, thus requiring a high stress to continue with the deformation process. Huang et al. [18] reported the hardening of the nanostructured pure aluminum by annealing. An annealing hardening behavior was also observed in the pure magnesium matrix processed by the cold hydrostatic extrusion [19]. The initial microstructure and its evolution during annealing are responsible for the annealing hardening behavior in the pure metals. It indicates that magnesium and its alloys with an appropriate initial microstructure would exhibit an annealing hardening behavior during annealing. It should be emphasized that no solute atom or second-phase particle is responsible for the observed annealing hardening behavior in pure magnesium. Instead, the evolution of the microstructure, e.g., the change in grain size and dislocation structure, may be responsible for the annealing hardening phenomenon in pure magnesium. However, it is challenging to obtain the microstructure suitable for the annealing hardening in magnesium and its alloys. Thus, only a few studies have reported the annealing hardening behavior in pure magnesium during annealing. In this study, a slight drop in the strength has been revealed upon subjecting the alloy to single annealing. It can be concluded that the microstructural evolution during single annealing has no annealing hardening effect for the alloy used in this study. The pinning of the gliding basal dislocation by the GP zones has also been reported in the magnesium alloy [20]. It has been concluded that the formation of the 
GP zones depends on the pre-existing plastic strain, thereby suggesting that the internal stresses inside a deformed material are beneficial in forming the GP zones. In the present study, the GP zones are not observed, thus indicating that the experimental conditions in the present study do not lead to the formation of the GP zones. Therefore, the effect of the GP zones on the gliding dislocations can be ignored in this study.

In summary, the appearance of the second-phase particles owing to the simultaneous annealing and loading leads to a remarkable strengthening effect in the AZ31 alloy. In addition, the solute segregation in the grain boundaries may also strengthen the material's properties.

\section{Conclusions}

The AZ31 alloy was subjected to the simultaneous annealing and loading, and the microstructural evolution and the influence on the mechanical properties were characterized. The major conclusions can be summarized as follows:

(1) Single annealing has no obvious effect on precipitation behavior in hot-extruded magnesium AZ31. However, the simultaneous annealing and loading has an obvious effect on precipitation behavior. A higher quantity of precipitates can be obtained after the processing of simultaneous annealing and loading. Furthermore, a higher stress will be more beneficial for precipitation in a same annealing time.

(2) On subjecting the AZ31 alloy to single annealing, a slight annealing softening effect is observed. However, the appearance of the second-phase particles during the simultaneous annealing and loading processes hinders the dislocation gliding, thereby leading to a strengthening effect in the AZ31 alloy. In addition, the solute segregation in grain boundaries also may strengthen the material

Author Contributions: Conceptualization and methodology, J.H.; formal analysis, L.W.; investigation and data curation, J.H. and L.W.; resources, J.H.; writing-original draft preparation, J.H.; writingreview and editing, L.W.; visualization, J.H.; supervision, J.H.; project administration, J.H.; funding acquisition, J.H. and L.W. All authors have read and agreed to the published version of the manuscript.

Funding: This work was supported by the National Natural Science Foundation of China (51501045) and Natural Science Foundation of Guizhou Province ([2019]1141).

Institutional Review Board Statement: Not applicable.

Informed Consent Statement: Not applicable.

Data Availability Statement: Not applicable.

Conflicts of Interest: The authors declare no conflict of interest.

\section{References}

1. Wang, C.; Cepeda-Jiménez, C.; Pérez-Prado, M. Dislocation-particle interactions in magnesium alloys. Acta Mater. 2020, 194, 190-206. [CrossRef]

2. Orozco-Caballero, A.; Lunt, D.; Robson, J.D.; Fonseca, J. How magnesium accommodates local deformation incompatibility: A high-resolution digital image correlation study. Acta Mater. 2017, 133, 367-379. [CrossRef]

3. Kim, Y.; Lee, J.U.; Kim, S.; Kim, Y.; Park, S. Grain size effect on twinning and annealing behaviors of rolled magnesium alloy with bimodal structure. Mater. Sci. Eng. A 2019, 754, 38-45. [CrossRef]

4. Liu, B.; Dong, G.; Ren, X.; Zhang, Y.; Wei, Y. Accelerated degradation rate of high-strength Mg-4Y-1Zn by Cu addition for degradable bridge-plug applications. Int. J. Mater. Res. 2020, 111, 872-875. [CrossRef]

5. Feng, J.; Li, X.; Sun, H.; Fang, W. An ultra-high strength Mg-3Al-Zn alloy with low tebsion-compression yield asymmetry. Mater. Lett. 2020, 269, 127489. [CrossRef]

6. Wei, X.; Li, J.; Wang, F.; Li, J.; Ye, N.; Zhang, Z. High strength and ductility Mg-8Gd-3Y-0.5Zr alloy with bimodal structure and nano-precipitates. J. Mater. Sci. Technol. 2020, 44, 19-23. [CrossRef]

7. Li, R.; Li, H.; Pan, H.; Xie, D.; Zhang, J.; Fang, D.; Dai, Y.; Zhao, D.; Zhang, H. Achieving exceptionally high strength in binary $\mathrm{Mg}-13 \mathrm{Gd}$ alloy by strong texture and Achieving exceptionally high strength in binary Mg-13Gd alloy by strong texture and substantial precipitates. Scr. Mater. 2021, 193, 142-146. [CrossRef]

8. Sulkowski, B.; Janoska, M.; Boczkal, G.; Chulist, R.; Mroczkowski, M.; Palka, P. The effect of severe plastic deformation on the Mg properties after CEC deformation. J. Magnes. Alloys 2020, 8, 761-768. [CrossRef] 
9. Yan, Z.; Zhang, Z.; Li, X.; Xu, J.; Wang, Q.; Zhang, G.; Zheng, J.; Fan, H.; Xu, K.; Zhu, J.; et al. A novel severe plastic deformation method and its effect on microstructure, texture and mechanical properties of Mg-Gd-Y-Zn-Zr alloy. J. Alloys Compd. 2020, 822, 153698. [CrossRef]

10. Zhong, L.; Wang, Y.; Luo, H.; Luo, C.; Peng, J. Evolution of the microstructure, texture and thermal conductivity of as-extruded ZM60 magnesium alloy in pre-compression. J. Alloys Compd. 2019, 775, 707-713. [CrossRef]

11. Song, B.; Guo, N.; Xin, R.; Pan, H.; Guo, C. Strengthening and toughening of extruded magnesium alloy rods by combining pre-torsion deformation with subsequent annealing. Mater. Sci. Eng. A 2016, 650, 300-304. [CrossRef]

12. Xin, Y.; Wang, M.; Zeng, Z.; Nie, M.; Liu, Q. Strengthening and toughening of magnesium alloy by $\{10-12\}$ extension twins. Scr. Mater. 2012, 66, 25-28. [CrossRef]

13. Nie, J.; Zhu, Y.; Liu, J.; Fang, X. Periodic segregation of solute atoms in fully coherent twin boundaries. Science 2013, 340, 957-960. [CrossRef]

14. Zhao, L.; Xin, Y.; Guo, F.; Yu, H.; Liu, Q. A new annealing hardening mechanism in pre-twinned Mg-3Al-1Zn alloy. Mater. Sci. Eng. A 2016, 654, 344-351. [CrossRef]

15. Chen, H.; Liu, T.; Zhang, Y.; Song, B.; Hou, D.; Pan, F. The yield asymmetry and precipitation behavior of pre-twinned ZK60 alloy. Mater. Sci. Eng. A 2016, 652, 167-174. [CrossRef]

16. Fu, H.; Guo, J.; Wu, W.; Liu, B.; Peng, Q. High pressure aging synthesis of a hexagonal $\mathrm{Mg}_{2} \mathrm{Sn}$ strengthening precipitate in $\mathrm{Mg}-\mathrm{Sn}$ alloys. Mater. Lett. 2015, 157, 172-175. [CrossRef]

17. He, J.; Wu, L.; Sun, Q.; Zhai, L. Precipitation behavior and its effects on mechanical properties in a pre-twinned Mg-6Al-1Zn alloy. Mater. Trans. 2018, 59, 1389-1395. [CrossRef]

18. Huang, X.; Hansen, N.; Tsuji, N. Hardening by annealing and softening by deformation in nanostructured metals. Science 2006, 312, 249-251. [CrossRef] [PubMed]

19. Volkov, A.; Kliukin, I. Improving the mechanical properties of pure magnesium through cold hydrostatic extrusion and lowtemperature annealing. Mater. Sci. Eng. A 2015, 627, 56-60. [CrossRef]

20. Zeng, Z.; Zhu, Y.; Bian, M.; Xu, S.; Davies, C.; Birbilis, N.; Nie, J. Annealing strengthening in a dilute Mg-Zn-Ca sheet alloy. Scr. Mater. 2015, 107, 127-130. [CrossRef] 